\title{
Front Matter: Volume 10237
}

, "Front Matter: Volume 10237," Proc. SPIE 10237, Advances in X-ray FreeElectron Lasers Instrumentation IV, 1023701 (3 July 2017); doi: $10.1117 / 12.2281162$

SPIE. Event: SPIE Optics + Optoelectronics, 2017, Prague, Czech Republic 


\title{
PROCEEDINGS OF SPIE
}

\section{Advances in X-ray Free-Electron Lasers Instrumentation IV}

\author{
Thomas Tschentscher \\ Luc Patthey \\ Editors
}

25-27 April 2017

Prague, Czech Republic

Sponsored by

SPIE

Cooperating Organisations

Science and Technology Facilities Council (United Kingdom)

ELI Beamlines (Czech Republic)

Laserlab Europe

AILU-Association of Laser Users (United Kingdom)

European Optical Society

HiLASE (Czech Republic)

AWE-Atomic Weapons Establishment (United Kingdom)

Published by

SPIE 
The papers included in this volume were part of the technical conference cited on the cover and title page. Papers were selected and subject to review by the editors and conference program committee. Some conference presentations may not be available for publication. The papers published in these proceedings reflect the work and thoughts of the authors and are published herein as submitted. The publisher is not responsible for the validity of the information or for any outcomes resulting from reliance thereon.

Please use the following format to cite material from these proceedings:

Author(s), "Title of Paper," in Advances in X-ray Free-Electron Lasers Instrumentation IV, edited by Thomas Tschentscher, LUC Patthey, Proceedings of SPIE Vol. 10237 (SPIE, Bellingham, WA, 2017) Seven-digit Article CID Number.

ISSN: 0277-786X

ISSN: 1996-756X (electronic)

ISBN: 9781510609754

ISBN: 9781510609761 (electronic)

Published by

SPIE

P.O. Box 10, Bellingham, Washington 98227-0010 USA

Telephone +1 3606763290 (Pacific Time) · Fax +1 3606471445

SPIE.org

Copyright (C) 2017, Society of Photo-Optical Instrumentation Engineers.

Copying of material in this book for internal or personal use, or for the internal or personal use of specific clients, beyond the fair use provisions granted by the U.S. Copyright Law is authorized by SPIE subject to payment of copying fees. The Transactional Reporting Service base fee for this volume is $\$ 18.00$ per article (or portion thereof), which should be paid directly to the Copyright Clearance Center (CCC), 222 Rosewood Drive, Danvers, MA 01923. Payment may also be made electronically through CCC Online at copyright.com. Other copying for republication, resale, advertising or promotion, or any form of systematic or multiple reproduction of any material in this book is prohibited except with permission in writing from the publisher. The CCC fee code is $0277-786 \mathrm{X} / 17 / \$ 18.00$.

Printed in the United States of America.

Publication of record for individual papers is online in the SPIE Digital Library.

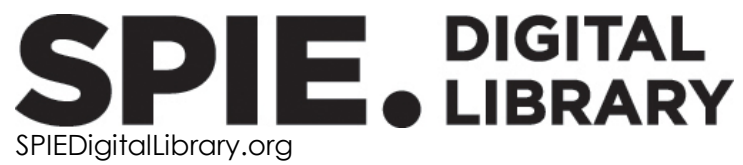

Paper Numbering: Proceedings of SPIE follow an e-First publication model, with papers published first online and then in print. Papers are published as they are submitted and meet publication criteria. A unique citation identifier (CID) number is assigned to each article at the time of the first publication. Utilization of CIDs allows articles to be fully citable as soon as they are published online, and connects the same identifier to all online, print, and electronic versions of the publication. SPIE uses a seven-digit CID article numbering system in which:

- The first five digits correspond to the SPIE volume number.

- The last two digits indicate publication order within the volume using a Base 36 numbering system employing both numerals and letters. These two-number sets start with $00,01,02,03,04$, $05,06,07,08,09,0 A, 0 B \ldots$. OZ, followed by 10-1Z, 20-2Z, etc.

The CID Number appears on each page of the manuscript. The complete citation is used on the first page, and an abbreviated version on subsequent pages. 


\title{
Contents
}

\author{
$\checkmark \quad$ Authors \\ vii Conference Committee \\ ix Introduction
}

STATUS AND DEVELOPMENT PLANS OF PLANNED AND OPERATIONAL VUV, EUV, SOFT X-RAY AND X-RAY FEL FACILITIES

1023706 Overview of optics, photon diagnostics and experimental instruments at SACLA:

development, operation and scientific applications (Invited Paper) [10237-5]

1023708 Commissioning for the European XFEL facility (Invited Paper) [10237-7]

10237 OC Four-wave-mixing experiments and beyond: the TIMER/mini-TIMER setups at FERMI (Invited Paper) [10237-11]

HIGH BRIGHTNESS AND ULTRASHORT X-RAY AND EUV SOURCES: JOINT SESSION WITH CONFERENCES 10237 AND 10243

10237 OF High quality electron beams for high quality FEL (Invited Paper) [10237-14]

FEL SCHEMES AND CHARACTERIZATION OF ELECTRON BEAM AND FEL RADIATION

10237 OG Innovative FEL schemes using variable-gap undulators (Invited Paper) [10237-15]

$10237 \mathrm{OH}$ Statistical characterization of an x-ray FEL in the spectral domain [10237-16]

10237 Ol Transverse coherence and pointing stability of the radiation from $\mathbf{x}$-ray free electron lasers [10237-17]

10237 OJ Radiation properties of the SASE3 afterburner for European XFEL [10237-18]

\section{CHARACTERIZATION OF FEL RADIATION}

10237 OK Development of a hard x-ray wavefront sensor for the EuXFEL (Invited Paper) [10237-19]

10237 OM Single-shot beam profile diagnostics for $\mathbf{x}$-ray FEL's using gas fluorescence [10237-21]

10237 ON Characterization of the LCLS "nanosecond two-bunch" mode for $x$-ray speckle visibility spectroscopy experiments [10237-22] 
X-RAY OPTICS AND BEAM TRANSPORT ISSUES INCLUDING PROPAGATION OF COHERENT $X$-RAY FEL RADIATION AND SIMULATION OF X-RAY FEL I

1023700 Ultrahigh performance mirrors for diffraction limited light sources (Invited Paper) [10237-23]

X-RAY OPTICS AND BEAM TRANSPORT ISSUES INCLUDING PROPAGATION OF COHERENT $X$-RAY FEL RADIATION AND SIMULATION OF X-RAY FEL II

10237 OR Development of a hard x-ray split-delay system at the Linac Coherent Light Source [10237-26]

10237 OS Simulations of ultrafast x-ray laser experiments (Invited Paper) [10237-27]

10237 OT Design of compressors for FEL pulses using deformable gratings [10237-28]

ADVANCED INSTRUMENTATION FOR FEL EXPERIMENTS IN THE AREAS OF SPECIAL X-RAY TECHNIQUES, SAMPLE ENVIRONMENT, DETECTORS AND LASERS

10237 OW Detector sustainability improvements at LCLS [10237-31]

POSTER SESSION

$10237 \mathrm{OZ}$ Magnetic force study for the helical afterburner for the European XFEL [10237-34]

1023710 Frequency doubler and two-color mode of operation at free electron laser FLASH2 [10237-35]

1023711 Application of statistical techniques for characterization of SASE FEL radiation [10237-36]

1023712 A soft $x$-ray split-and-delay unit for FLASH II [10237-37]

1023713 A hard $x$-ray split-and-delay unit for the HED instrument at the European XFEL [10237-38]

1023714 Duty-cycle dependence of the filamentation effect in gas devices for high repetition rate pulsed x-ray FEL's [10237-39]

1023716 Grating monochromator with ultrafast response for FLASH2 at DESY [10237-41] 


\section{Authors}

Numbers in the index correspond to the last two digits of the seven-digit citation identifier (CID) article numbering system used in Proceedings of SPIE. The first five digits reflect the volume number. Base 36 numbering is employed for the last two digits and indicates the order of articles within the volume. Numbers start with 00, 01, 02, 03, 04, 05, 06, 07, 08, 09, OA, OB...0Z, followed by 10-12, 20-2Z, etc.

\author{
Allaria, E., OF \\ Alonso-Mori, Roberto, OM \\ Andreev, A. A., OS \\ Appel, Karen, OS, 13 \\ Barada, Andrew H., OR \\ Bencivenga, Filippo, OC \\ Berujon, Sebastien, OK \\ Bonora, Stefano, OT \\ Branco, J., OS \\ Braun, Stefan, 13 \\ Brenner, Günter, 16 \\ Briggs, R., OS \\ Browne, Michael C., OW \\ Bussmann, M., OS \\ Buzmakov, A., OS \\ Calvi, Andrea, OC \\ Capotondi, Flavio, OC \\ Carini, Gabriella, OW \\ Chollet, Matthieu, OM \\ Cojocaru, Ruxandra, OK \\ Cucini, Riccardo, OC \\ Damiani, Daniel S., OM \\ Decker, Franz-Josef, ON \\ DePonte, Daniel P., OW \\ Fabris, Nicola, OT \\ Feng, Yiping, $\mathrm{OH}, \mathrm{OM}, 14$ \\ Foglia, Laura, OC \\ Fortmann-Grote, C., OS \\ Frassetto, Fabio, OT, 16 \\ Freijo-Martin, I., 00 \\ Fuoss, Paul H., ON \\ Galtier, Eric C., OW \\ Garten, M., OS \\ Gawlitza, Peter, 13 \\ Giovine, Ennio, OT \\ Glownia, James M., OM \\ Grübel, Gerhard, ON \\ Grund, A., OS \\ Gumerlock, Karl L., OR \\ Hart, Philip A., OW \\ Hastings, Jerome B., OM \\ Hruszkewycz, Stephan, ON \\ Huang, Zhirong, $\mathrm{OH}$ \\ Huebl, A., OS \\ Inove, Ichiro, 06 \\ Inubushi, Yuichi, 06 \\ James, Justin $\mathrm{H} ., \mathrm{OR}$ \\ Jurek, Z., OS \\ Kärcher, Victor, 13
}

Katayama, Tetsuo, 06

Kiskinova, Maya, OC

Kon, Akira, 06

Koralek, J. D., OW

Koyama, Takahisa, 06

Krzywinski, Jacek, $\mathrm{OH}$

Kuhlmann, Marion, 10, 12, 16

Li, Peng, OJ, OZ

Li, Yuhui, OJ, OZ

Loh, N. D., OS

Ludwig, Karl, ON

Lutman, Alberto, $\mathrm{OH}$

Mahne, Nicola, OC

Mancuso, A. P., OS

Manfredda, Michele, OC

Martin, Thierry, OK

Masciovecchio, Claudio, OC

Mincigrucci, Riccardo, OC

Miotti, Paolo, OT

Mitra, Ankush, OW

Nakahara, Kazutaka, OW

Nakatsutsumi, M., OS

Nelson, Silke, OM

Nicolas, Josep, OR

Nölle, D., 08

Ohashi, Haruhiko, 06

Osaka, Taito, 06

Osier, Ted O., OR

Owada, Shigeki, 06

Pedersoli, Emanuele, $\mathrm{OC}$

Pflueger, Joachim, OJ, OZ

Plönjes, Elke, 12, 16

Poletto, Luca, OT, 16

Principi, Emiliano, 0C

Quintavalla, Martino, OT

Raimondi, Lorenzo, OC

Raubenheimer, Tor O., 14

Robert, Aymeric, OM, ON, OR

Roling, Sebastian, 12, 13

Rollnik, Matthias, 12, 13

Roseker, Wojciech, ON

Samoylova, Liubov, OS, 13

Santra, R., OS

Schafer, Donald W., OR

Schneidmiller, E. A., OG, OI, OS, 10, 11

Sharma, A., OS

Shi, Hongliang, OR

Siewert, Frank, 13

Simoncig, Alberto, OC 
Smith, Brian, OR

Song, Sanghoon, OM, ON

Steiniger, K., OS

Stephenson, G. Brian, ON

Sun, Yanwen, ON, OR

Sutton, Mark, ON

Togashi, Tadashi, 06

Tono, Kensuke, 06

Vannoni, M., 00

Wahlert, Frank, 12, 13

Wei, Tao, OJ, 0 Z

Weninger, Clemens, OM

Whitney, Randy, OR

Wu, Juhao, $\mathrm{OH}$

Yabashi, Makina, 06

Yabuuchi, Toshinori, 06

Yakubov, S., OS

Yoon, C. H., OS

Yumoto, Hirokatsu, 06

Yurkov, M. V., OG, OI, OS, 10, 11

Zacharias, Helmut, 12, 13

Zangrando, Marco, OC

Zastrau, UIf, OS, 13

Zhang, Lin, $O R$

Zhu, Diling, $\mathrm{OH}, \mathrm{OM}, \mathrm{ON}, \mathrm{OR}$

Ziaja-Motyka, B., OS

Ziegler, Eric, OK 


\title{
Conference Committee
}

\author{
Symposium Chairs
}

Jiri Homola, Institute of Photonics and Electronics of the ASCR, v.v.i. (Czech Republic)

Bedrich Rus, Institute of Physics of the ASCR, v.v.i. (Czech Republic)

Chris Edwards, Central Laser Facility, Science and Technology

Facilities Council (United Kingdom)

Mike Dunne, SLAC National Accelerator Laboratory (United States) and Linac Coherent Light Source (United States)

Ivo Rendina, Istituto per la Microelettronica e Microsistemi, CNR (Italy)

\section{Conference Chairs}

Thomas Tschentscher, European XFEL GmbH (Germany)

Luc Patthey, Paul Scherrer Institut (Switzerland)

Conference Programme Committee

Sven Reiche, Paul Scherrer Institut (Switzerland)

Aymeric Robert, SLAC National Accelerator Laboratory

(United States)

Rolf Treusch, Deutsches Elektronen-Synchrotron (Germany)

Makina Yabashi, Japan Synchrotron Radiation Research Institute (JASRI) (Japan)

Mikhail V. Yurkov, Deutsches Elektronen-Synchrotron (Germany)

Marco Zangrando, Elettra-Sincrotrone Trieste S.C.p.A. (Italy)

Philippe Zeitoun, Laboratoire d'Optique Appliquée (France)

Session Chairs

Scientific Applications of Laser- and Accelerator-based X-ray

Sources: Joint Session with Conferences 10237 and 10243

Thomas Tschentscher, European XFEL GmbH (Germany)

Temporal, Spatial and Coherence Diagnostics of Ultrashort X-ray Pulses: Joint Session with Conferences 10237 and 10243

Carmen S. Menoni, Colorado State University (United States)

Status and Development Plans of Planned and Operational VUV, EUV, Soft X-ray and X-ray FEL Facilities

Rolf Treusch, Deutsches Elektronen-Synchrotron (Germany) 
High Brightness and Ultrashort X-ray and EUV Sources: Joint Session with Conferences 10237 and 10243

Annie Klisnick, Université Paris-Sud 11 (France)

FEL Schemes and Characterization of Electron Beam and FEL Radiation

Luc Patthey, Paul Scherrer Institut (Switzerland)

Characterization of FEL Radiation

Mikhail V. Yurkov, Deutsches Elektronen-Synchrotron (Germany)

X-ray Optics and Beam Transport Issues Including Propagation of Coherent X-ray FEL Radiation and Simulation of X-ray FEL I

Luc Patthey, Paul Scherrer Institut (Switzerland)

X-ray Optics and Beam Transport Issues Including Propagation of Coherent X-ray FEL Radiation and Simulation of X-ray FEL II Luc Patthey, Paul Scherrer Institut (Switzerland)

Advanced Instrumentation for FEL Experiments in the Areas of Special X-ray Techniques, Sample Environment, Detectors and Lasers

Thomas Tschentscher, European XFEL GmbH (Germany) 


\section{Introduction}

Free-electron laser (FEL) user facilities for the short-wavelength regime from vacuum-ultraviolet to hard $x$-rays are operational for more than a decade now. In Europe FLASH (Hamburg) and FERMI (Trieste), world-wide LCLS (Menlo Park, U.S.A.), SACLA (Harima, Japan) and PAL-XFEL (Pohang, South Corea; from 2017) are the facilities to be listed here. In Europe, two new facilities with presently nine end-stations for experiments turn on in the current year: SwissFEL (Villigen) and European XFEL (Hamburg). X-ray FEL radiation provides exquisite beam properties in terms of pulse duration, coherence, and pulse energy. High repetition rate facilities like FLASH and European XFEL also provide high average flux. Shortwavelength FELs combine features of conventional $x$-ray sources and of ultrashort and highly intense optical laser sources. At the same time the FEL sources are highly complementary to these x-ray sources, like e.g. provided by synchrotron radiation from storage rings, and optical laser sources.

In the past decade $x$-ray FEL radiation has already been applied to a large number of high profile scientific applications reaching from physics, over chemistry, material and earth sciences to biology. Many of these applications were enabled by employing state-of-the-art developments of the FEL sources and their properties, of new x-ray and optical laser techniques, and of new instrumentation developed for and at the FEL facilities. Vice-versa, science applications generated additional and new requirements for the further development of the FEL sources, x-ray techniques and their instrumentation. This very dynamic field of development of FEL sources and instrumentation for $x$-ray FEL experiments has led to a large number of new results in many different areas since this conference was held last, two years ago.

The conference therefore has a specific focus on these new developments and on scientific applications requiring these developments. The conference itself and the papers in this proceeding volume address new and outstanding scientific applications of x-ray FELs, the start of new FEL facilities and the further development of existing ones, the development of new FEL and similar radiation schemes, the progress with high quality $x$-ray optics designed for general and specific applications, the development and implementation of x-ray diagnostics methods, and the further development and the implementation of ancillary instrumentation like detectors and laser systems, which are so important for the success of experiments using these large scale user facilities. Specific topics are the current developments in the areas of special FEL schemes and the major development activities with respect to providing high average brightness and ultrahigh peak brightness.

In 2017 part of this conference was organized jointly with the conference on " $X$ Ray Lasers and Coherent X-Ray Sources: Development and Applications" [1]. Joint sessions were held on the topics "high brightness and ultrashort $\mathrm{x}$-ray and 
EUV sources", "scientific applications of laser- and accelerator-based x-ray sources" and "temporal, spatial and coherence diagnostics of ultrashort x-ray pulses". These areas represent a highly common interest, both in terms of method developments and scientific application.

Thomas Tschentscher Luc Patthey

\section{REFERENCES}

[1] A. Klisnick, C. Menoni (eds.), X-Ray Lasers and Coherent X-Ray Sources: Development and Applications, Proceedings of SPIE 10243, Prague, 24. 27. April 2017 